International Journal of System Signal Control and Engineering Application 4 (4-6): 62-68, 2011

ISSN: $1997-5422$

(C) Medwell Journals, 2011

\title{
Design and Analysis of a Hybrid Fuzzy-Based Optimal Control over Induction Motors at Load Variation
}

\author{
Mohammad Abu Zalata \\ Department of Mechatronics Engineering, Faculty of Engineering Technology, \\ Al-Balqa Applied University, P.O. Box 425530, 11140 Amman, Jordan
}

\begin{abstract}
This study is concerning with developing a hybrid optimal control technique for a 3-ph induction motor submitted to load variation. This approach is derived and implemented with MatLab/SimuLink environment. It aims to reduce the power consumption of such motors in order to reduce the total cost and enhance the motor performance in industry. The method used is the stator current optimization. A classical control approach is firstly, considered and then compared with a developed hybrid control one using rule-based fuzzy logic system. Finally, numerical results have been added to confirm the validation of the proposed control technique.
\end{abstract}

Key words: Hybrid optimal control, fuzzy logic, power consumption, variable frequency drive, current, cost

\section{INTRODUCTION}

Induction Motors (IMs) with squirrel-cage are widely used in industrial environments because of their low cost and rotors rugged construction. In the last few decades, the induction motor has evolved from being a constant speed motor to be a variable speed, variable torque machine. Its evolution was challenged by the easiness of controlling a DC motor at low power application. When application require large amounts of power and torque, the induction motor becomes more efficient to use. With the invention of Variable Voltage Variable Frequency inverter (VVVF); the use of an induction motor has increased. The formulation of new control systems has lead to the induction motor replacing the DC motors as the main source of energy conversion in industrial application. The induction motor has disadvantages that it has more losses and less efficiency when it works at variable speeds. The need of suitable system was achieved by special controllers that not only modify the losses and efficiency but also searching for the optimal values of stator current to reduce the power consumption from the source to be minimum. The trends of designing optimal controllers was developed due to the increasing in power consumption which represents the most important problem in the world due to the decreasing in power resources in the last few decades and increased the cost of electrical power generation by petroleum fuel. The studies proved that there is a possibility to decrease the power consumption and increase the efficiency of used IM. Induction motors are highly efficient at rated load and have efficiencies in the range $85-95 \%$. Motor losses consist of three main components; friction and windage, iron and copper losses. Friction and windage losses are insensitive to load changes as speed is essentially constant. Coming to the loss variations with reduction in voltage the iron loss comes down. And initially, the currents and hence copper losses also come down. When the voltage is reduced to sufficiently low level, the consequent increase in copper losses will at some point turn the total losses away from its decreasing trend, i.e., there will be one particular voltage at which the total losses in the motor will be a minimum. This voltage value will not coincide with the voltage value at which the current is a minimum at the same loading level but they will be close.

The most important challenge to reducing motor power consumption is to properly vary the shaft speed of motors that are designed as constant speed machines. Manufacturing machines, compressors, pumps, fans and most other motor drive loads vary with time of day, season and production requirements. The efficiency of a constant-speed induction motor can drop drastically under reduced loads, especially loads $<50 \%$ of the rated torque. Flow control by throttling not only wastes power in constant-speed motors but also increases fan, compressor or pump system friction losses. To minimize power losses, it is necessary to control motor speed.

With the assumption that the speed of the motor does not vary with reduction in voltage the minimum current point will coincide with maximum power factor (or minimum phase angle) condition. Similarly, the minimum loss point (i.e., maximum efficiency point) will coincide with minimum power input point. Minimum current point 
does not correspond to maximum efficiency point as already mentioned but they are close. But if the small variation in motor speed and consequent changes in output power are also considered, the optimum voltage point for a particular load condition in the four cases, i.e., the minimum current point, the minimum power factor angle point, the minimum power input point and the minimum loss (maximum efficiency) point will be different. The minimum loss point is difficult to monitor electronically though that is what we want to do. However, the other three conditions can be monitored electronically by sensing motor voltage and current and using some form of a minimum search algorithm implemented either digitally or in analog circuits. Of course, the loss reduction achieved will be less than optimal. Minimum power condition is the closest to maximum efficiency condition followed closely by current minimum condition. It is easier to process the current minimum search and hence it is current minimum search that is employed in most of the smart motor controllers available in the market (Kim, 2007).

The amount of energy savings possible depends on the extent of loading on the motor and its duty cycle. It also depends very much on the optimal operation algorithm implemented in the controller. Indicative figures on possible energy savings arrived at by a Westinghouse Corporation Study (Mohamed, 2001).

In this research, this method is used to supply the motor with optimal value of stator voltage to get minimum current to motor that suitable for the load; the optimal controller in this case generate control signal to voltage source inverter to control of voltage and frequency that operate the motor, the feedback to the controller is load torque as shown in Fig. 1.

The optimal control system is a programmable controller and has the ability to self searching for the optimal values of some variables when the changes affect the process. There are many variables that we can optimize in the induction motor. Some of these variables are: The minimum stator current $\left(\mathrm{I}_{\min }\right)$, the maximum efficiency $\left(\eta_{\max }\right)$ and the minimum total losses $\left(\mathrm{P}_{\text {losses }}\right)$. The purpose of this research is to optimize the stator current $\left(I_{\min }\right)$ to a minimum value so the power consumption could be minimized and the efficiency could be improved (Pryymak et al., 2006). With classical optimal control system, the feedback is load torque and the manipulated variable is the modulation index that considered as a control signal of the inverter to manipulate the stator voltage then the stator to reach their optimal values (minimum ones).

While with Fuzzy Logic Control (FLC), the feedback is stator voltage that is converted into modulation index

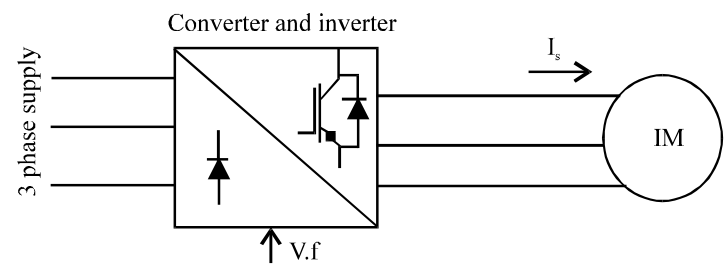

Fig. 1: Current optimization controller's V/F control

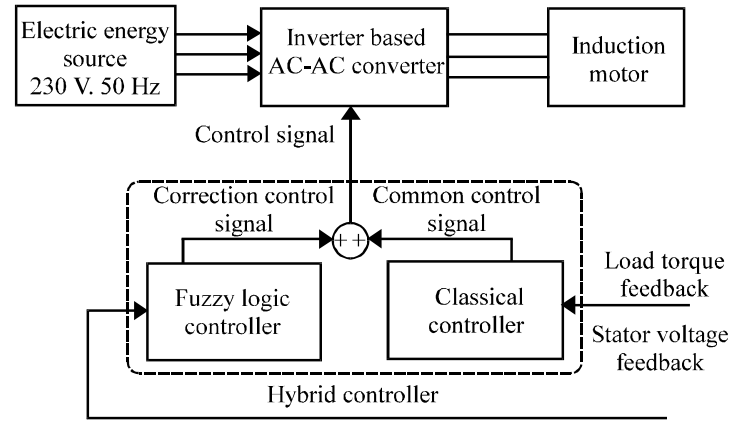

Fig. 2: Hybrid control system

MI by dividing it over nominal stator voltage and the manipulated variable is the correction command of the Modulation Index $(\Delta \mathrm{MI})$ that is performed as a control signal of the inverter to justify the minimum stator current value as shown in Fig. 2.

\section{MATERIALS AND METHODS}

Classical optimal control system: Any mathematical model must simplify the real-world situation in order to make analysis and computation practicable there is always a matter of judgment as to which real-world features must be retained in the model. Optimal control models are quite often inadequate concerning stability (Gnacinski, 2007). The principle of classical optimal control depend using the fitting options in Matlab to derive the stator voltage as a function of stator current at constant load, the minimum point in the curve calculated by using the Gradient Method $(\mathrm{SS} d \mathrm{dV} / \mathrm{dI})=$ zero by repeating this procedure on different loads less the rated load (in this project rated load is 18), researchers get the minimum point for V-I curve as shown in Fig. 3. The block diagram of classical optimal control system is as shown in Fig. 2. As mentioned before, the optimal current and corresponding voltage at different loads can be obtained by varying the stator voltage throughout varying the modulation index. With these minimum points which have value less than the nominal value, the motor can research with better performance. The minimum points for different loads were calculated and drawn on V-I curve as shown 
Table 1: Optimal voltage and current

\begin{tabular}{lcc}
$\mathrm{TL}(\mathrm{Nm})$ & $\mathrm{V}_{\min }[\mathrm{V}]$ & $\mathrm{I}_{\min }[\mathrm{A}]$ \\
\hline 2 & 97.5 & 1.722 \\
4 & 126.6 & 2.540 \\
6 & 154.7 & 3.112 \\
8 & 178.5 & 3.653 \\
10 & 196.7 & 0.168 \\
12 & 212.6 & 4.871 \\
14 & 225.3 & 5.166 \\
16 & 236.1 & 5.981 \\
18 & 242.6 & 6.319 \\
\hline
\end{tabular}

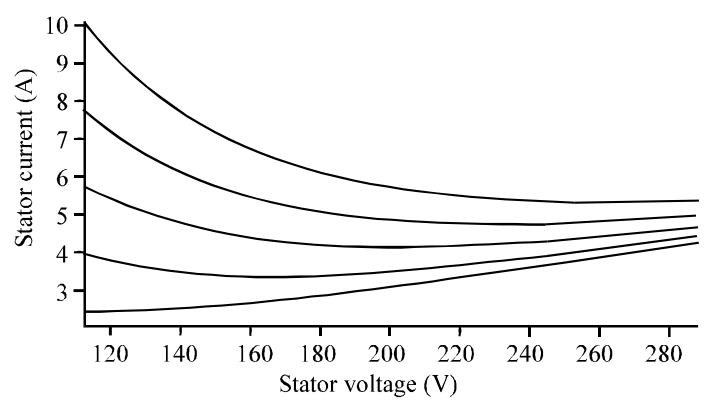

Fig. 3: Optimal currents and corresponding voltage at different load

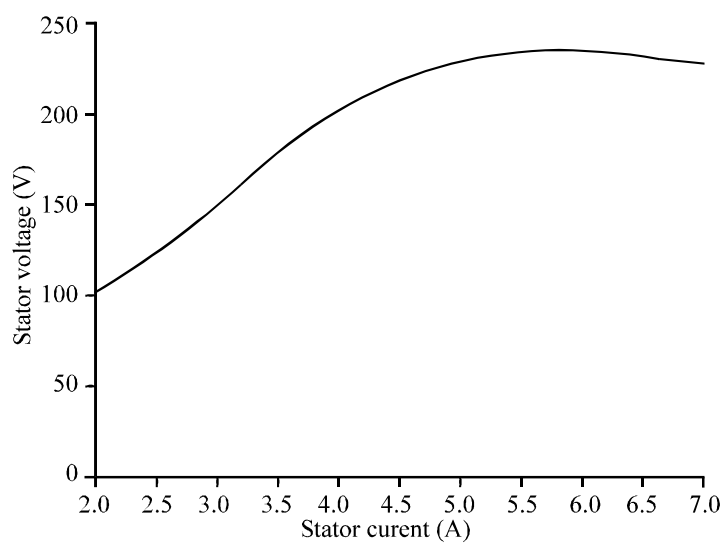

in Fig. 4. Optimal voltage and currents at variant loads could be concluded (Table 1) by V-I curve fitting of variant loads at nominal frequency. Using the previous data shown on Table 1, the controller's curve and equation at nominal frequency could be obtained using the curve fitting toolbox:

$$
\mathrm{V}_{\mathrm{s}}=\mathrm{f}^{5}\left(\mathrm{I}_{\mathrm{s}}\right)
$$

Where:

$\mathrm{V}_{\mathrm{s}}=$ The stator voltage

$\mathrm{I}_{\mathrm{s}} \quad=$ The stator current

$a_{1-5}=$ The operators of the polynomial, they are constants and equal to $0.351,-7.615,54.92,-119$ and 163.2 , respectively (Fig. 5)

By following the same technique were built many controllers for different frequencies that use the information on the load torque in order to generate the appropriate voltage by dividing this value on the nominal voltage $(230 \mathrm{~V})$, researchers get a new modulation index that lead to run the motor on the optimal parameters instead of nominal parameters. The classical system

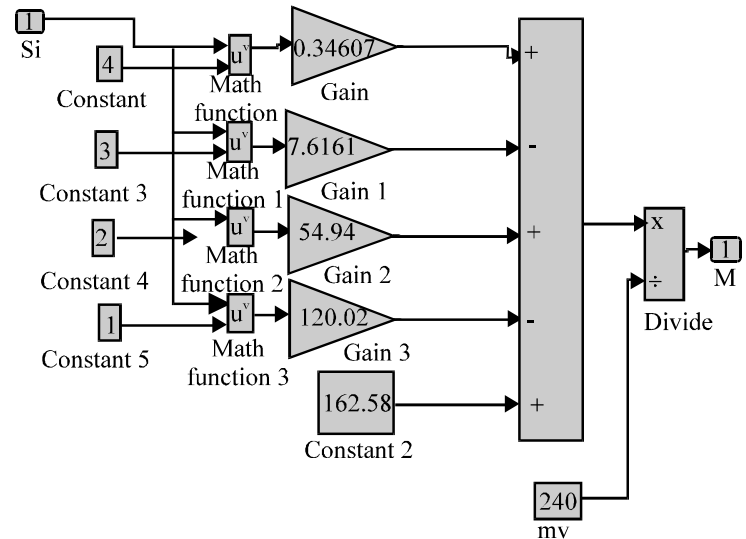

Fig. 5: Block diagram for equation at nominal frequency

Fig. 4: Optimal curve

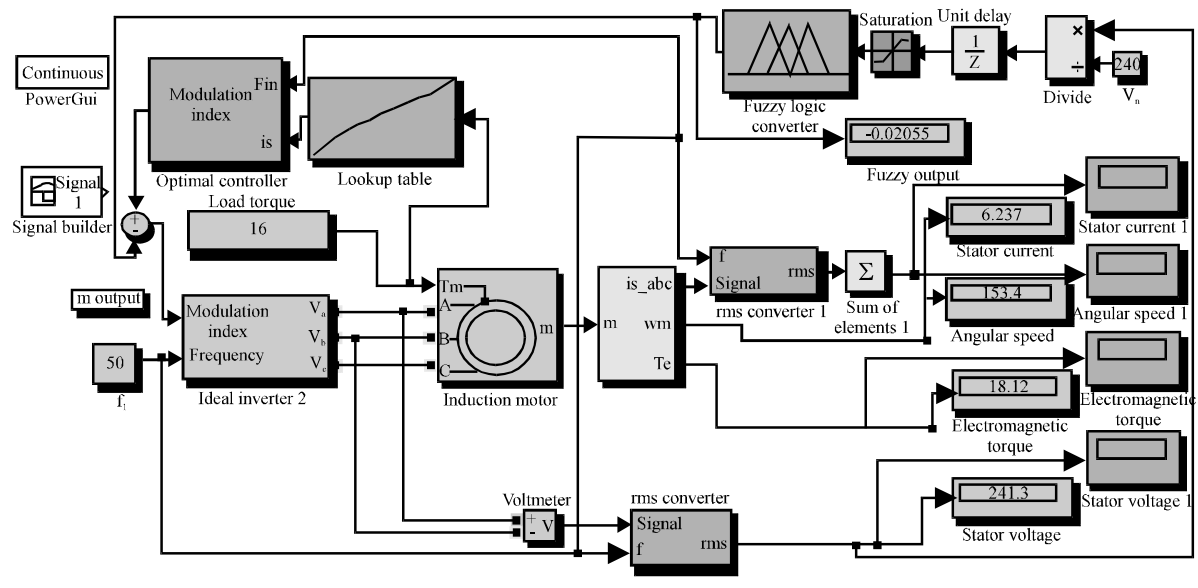

Fig. 6: Hybrid system 


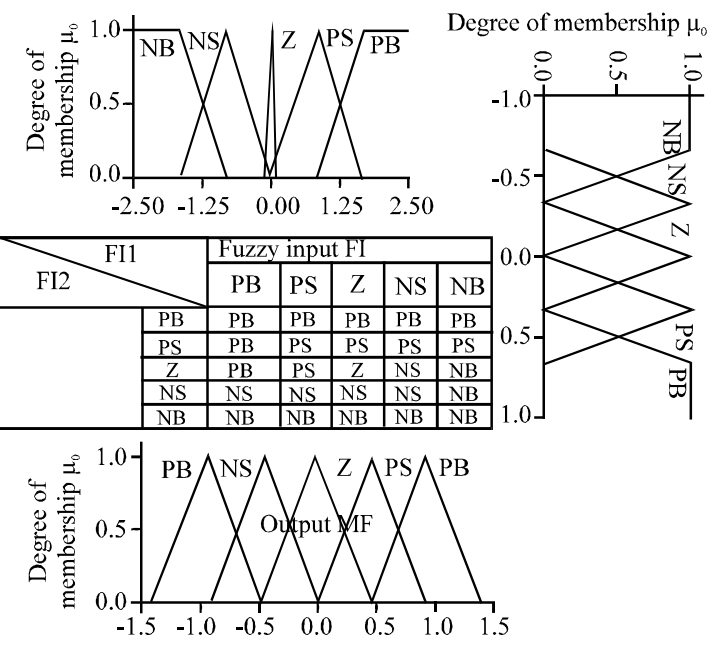

Fig. 7: FL truth table

response is fast; the moment the torque is changed, the controller calculates the appropriate command and output the desired voltage for that specific load to run on the optimal current. The resulting current using this method is very close to the optimal value but some errors exist, the accuracy can be increased by using additional searching systems Fuzzy Logic Controller (FLC) (Serway and Jewett, 2004; Tipler, 2004).

Hybrid control system: The results achieved by the classical control method can be enhanced by combining it with the Fuzzy Logic Controller (FLC) to invest the benefits found with each Fig. 6 . It joins the fast response advantage of the classical system with the higher accuracy of the searching system (i.e., FLC), the output of the hybrid system is exactly like the one of the search method except that the results are obtained much faster. The fuzzy logic truth table and membership function is as shown in Fig. 7. Where, $\mathrm{MI}_{(\mathrm{n}-1)}$ is the first normalized fuzzy input FI1 and refers to the previous value of modulation index, $V_{s}$ is the second normalized fuzzy input FI2 and refers to stator voltage, $\Delta \mathrm{MI}$ is the normalized fuzzy output and refers to the predicted deviation of the modulation index, Z: Zero (midpoint), PB: Positive Big, PS: Positive Small, NS: Negative Small, NB: Negative Big (Gerla, 2005). It should be noticed here, the mid-point MF of the FI1 has been narrowed to modify the controller response with maintaining stability.

\section{RESULTS AND DISCUSSION}

The simulation results of both the classical and hybrid optimal control approaches are shown in Table 2 and 3 , Fig. 8 and 9.

Comparative results: From Fig. 10 and 11, it could be concluded that the hybrid control method justifies the
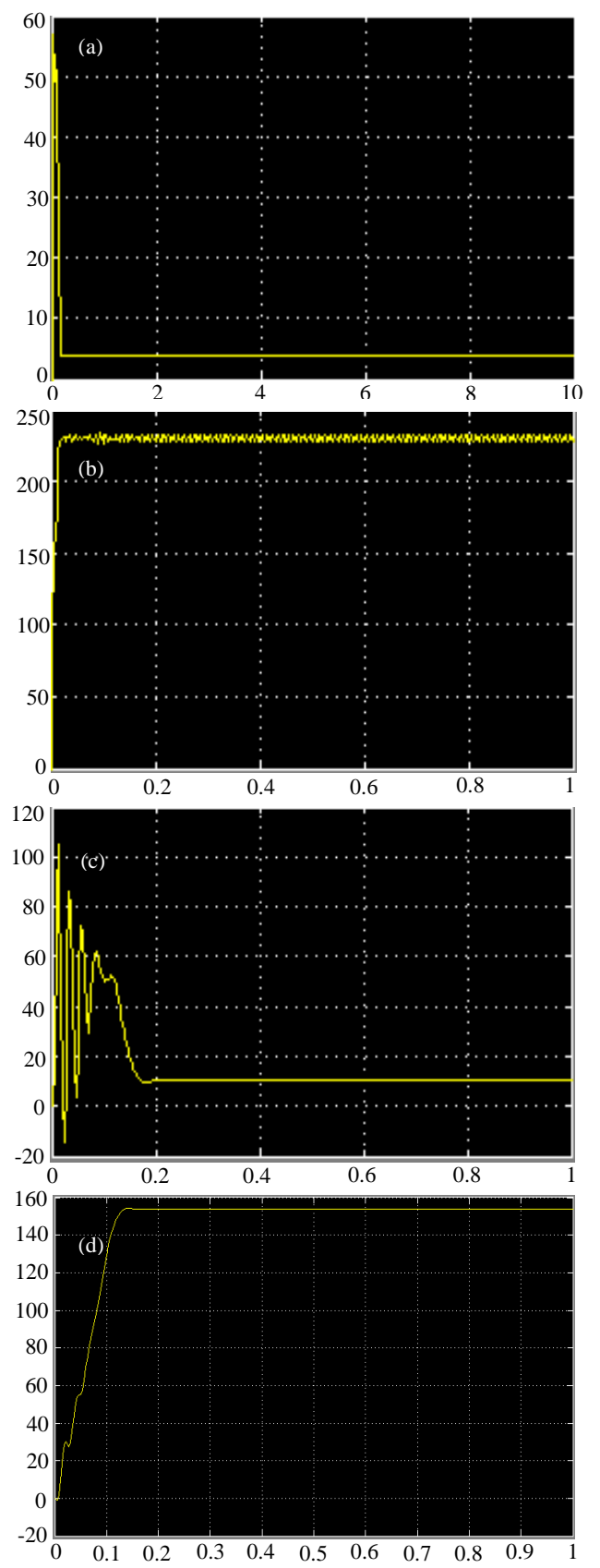

Fig. 8: Dynamic and steady-state performance of IM at $\mathrm{T}_{\mathrm{L}}=15 \mathrm{Nm}$; a) stator current; b) stator voltage; c) producing torque and d) angular speed

minimum optimal value of the stator current. In other words, the efficiency could be maximized when the load torque increases. The power could be also saved when comparing the proposed hybrid approach with the classical one at load changes (Table 4).

Table 5 explains the power consumption and power saving achieved by the hybrid optimal method 
Int. J. Syst. Signal Control Eng. Appl., 4 (4-6): 62-68, 2011
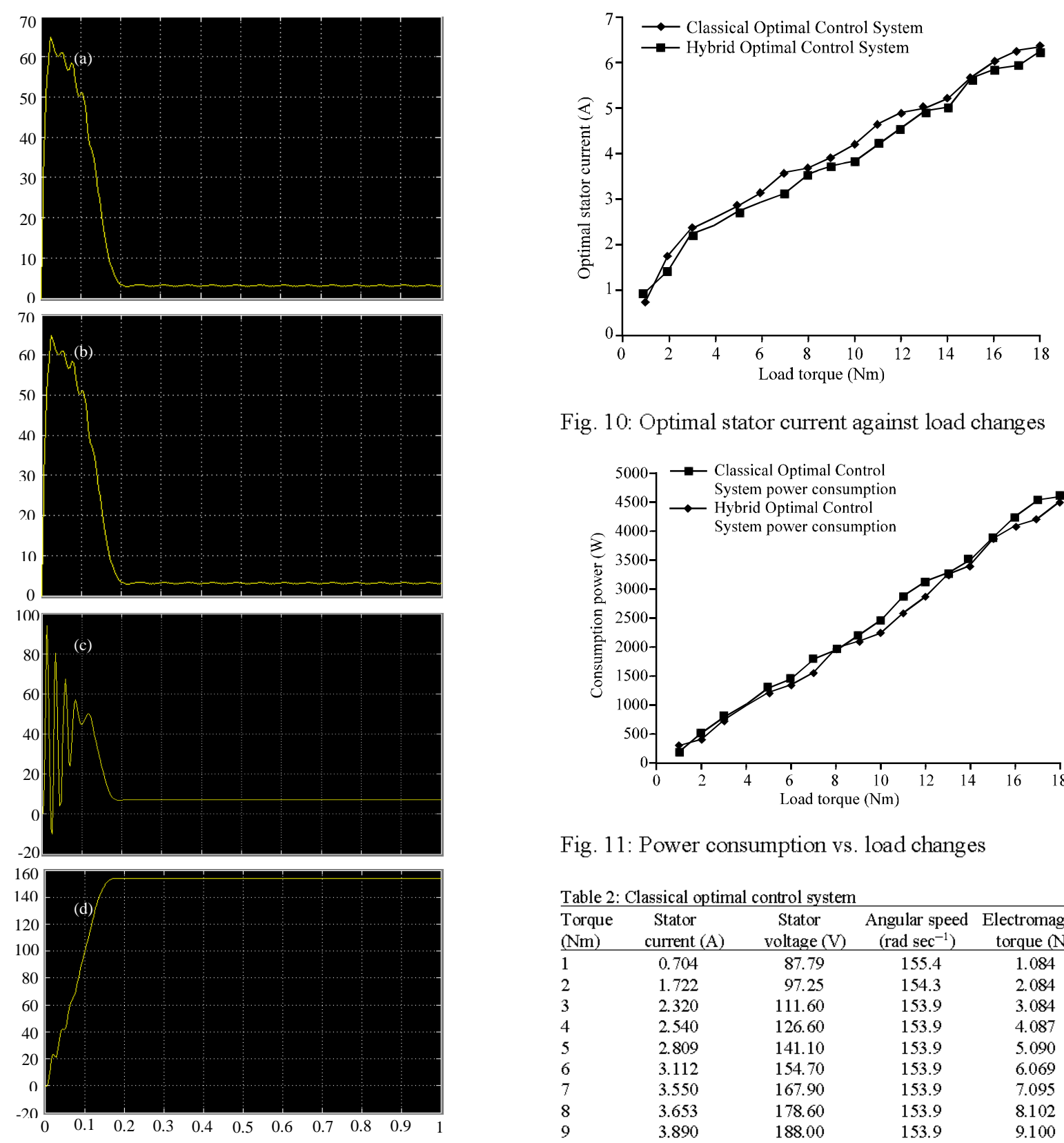

Fig. 10: Optimal stator current against load changes

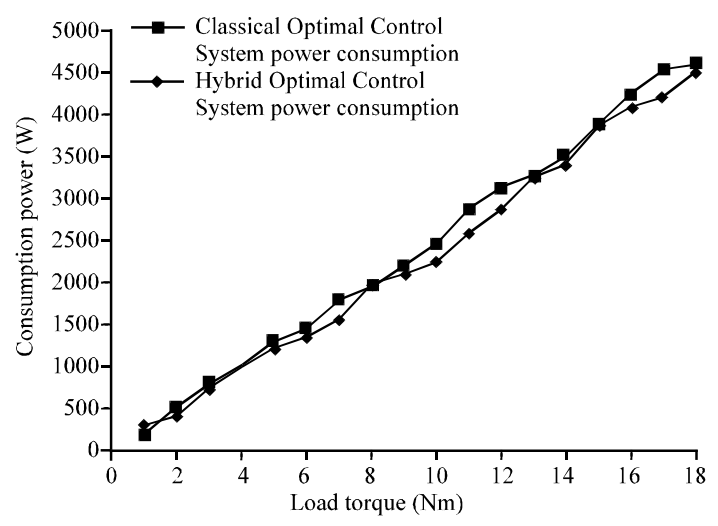

Fig. 11: Power consumption vs. load changes

\begin{tabular}{lcccc}
\multicolumn{5}{l}{ Table 2: Classical optimal control system } \\
$\begin{array}{l}\text { Torque } \\
(\mathrm{Nm})\end{array}$ & $\begin{array}{c}\text { Stator } \\
\text { current (A) }\end{array}$ & $\begin{array}{c}\text { Stator } \\
\text { voltage (V) }\end{array}$ & $\begin{array}{c}\text { Angular speed } \\
\left(\mathrm{rad} \mathrm{sec}^{-1}\right)\end{array}$ & $\begin{array}{c}\text { Electromagnetic } \\
\text { torque (Nm) }\end{array}$ \\
\hline 1 & 0.704 & 87.79 & 155.4 & 1.084 \\
2 & 1.722 & 97.25 & 154.3 & 2.084 \\
3 & 2.320 & 111.60 & 153.9 & 3.084 \\
4 & 2.540 & 126.60 & 153.9 & 4.087 \\
5 & 2.809 & 141.10 & 153.9 & 5.090 \\
6 & 3.112 & 154.70 & 153.9 & 6.069 \\
7 & 3.550 & 167.90 & 153.9 & 7.095 \\
8 & 3.653 & 178.60 & 153.9 & 8.102 \\
9 & 3.890 & 188.00 & 153.9 & 9.100 \\
10 & 4.165 & 196.70 & 153.8 & 10.110 \\
11 & 4.630 & 206.80 & 153.8 & 11.110 \\
12 & 4.871 & 212.60 & 153.7 & 12.110 \\
13 & 4.972 & 219.80 & 153.6 & 13.100 \\
14 & 5.166 & 225.30 & 153.6 & 14.180 \\
15 & 5.622 & 230.40 & 153.5 & 15.110 \\
16 & 5.981 & 236.10 & 153.4 & 16.110 \\
17 & 6.247 & 241.70 & 153.3 & 17.100 \\
18 & 6.391 & 242.60 & 153.2 & 18.110 \\
\hline
\end{tabular}

used is of $6 \mathrm{HPAC}$ power rating. It presented in textile machines in small factory that contains of $30 \mathrm{AC}$ motors that are same in characteristics.

The motor used in this study operates with continuous periodic duty cycle equal to $18 \mathrm{~h}$ at load diagram. The three cases found in the table are as following:

- Operating the motors at rated voltage and current without any method of control

- Operating the motors under Classical Optimal Control System

- Operating the motors under Hybrid Optimal Control System 
When realizing the three models of control (open loop, classical automated one and the proposed hybrid

Table 3: Hybrid optimal control system

\begin{tabular}{lcccc}
\hline $\begin{array}{l}\text { Load torque } \\
(\mathrm{Nm})\end{array}$ & $\begin{array}{c}\text { Stator } \\
\text { current }(\mathrm{A})\end{array}$ & $\begin{array}{c}\text { Stator } \\
\text { voltage (V) }\end{array}$ & $\begin{array}{c}\text { Angular speed } \\
\left(\mathrm{rad} \mathrm{sec}^{-1}\right)\end{array}$ & $\begin{array}{c}\text { Electromagnetic } \\
\text { torque (Nm) }\end{array}$ \\
\hline 1 & 1.1 & 89.9 & 155.5 & 1.079 \\
2 & 1.4 & 98.9 & 154.6 & 2.080 \\
3 & 2.2 & 111.4 & 154.1 & 3.100 \\
4 & 2.6 & 125.6 & 154.0 & 4.080 \\
5 & 2.8 & 143.5 & 154.0 & 5.078 \\
6 & 2.9 & 155.6 & 154.0 & 6.090 \\
7 & 3.1 & 166.1 & 154.0 & 7.088 \\
8 & 3.6 & 180.3 & 154.0 & 8.100 \\
9 & 3.7 & 188.7 & 154.0 & 9.100 \\
10 & 3.8 & 196.4 & 154.0 & 10.120 \\
11 & 4.2 & 203.9 & 153.9 & 11.120 \\
12 & 4.5 & 211.8 & 153.9 & 12.100 \\
13 & 4.9 & 219.2 & 253.8 & 13.090 \\
14 & 5.3 & 225.1 & 153.7 & 15.070 \\
15 & 5.6 & 229.9 & 153.7 & 15.070 \\
16 & 5.8 & 233.7 & 153.6 & 16.078 \\
17 & 5.9 & 237.8 & 153.5 & 17.130 \\
18 & 6.2 & 241.0 & 153.4 & 18.060 \\
\hline
\end{tabular}

optimal one), the results are as shown in Table 6. Table 6 explains the operating cost and the operating cost saving in Jordanian Dinars (JD) when comparing the three cases of control mentioned before. From discussion, researchers could conclude the followings:

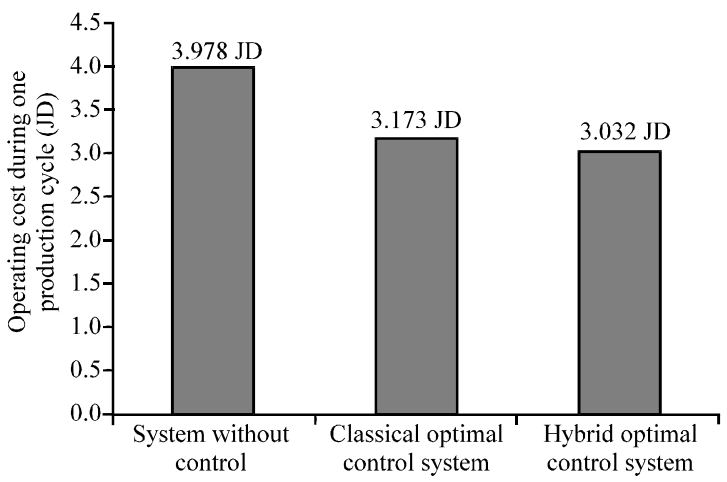

Fig. 12: Power consumption of three cases during production cycle

Table 4: Comparison between classical and hybrid optimal control

\begin{tabular}{|c|c|c|c|c|c|c|}
\hline $\begin{array}{l}\text { Load } \\
\text { torque }(\mathrm{Nm})\end{array}$ & $\begin{array}{l}\text { Classical stator } \\
\text { current (A) }\end{array}$ & $\begin{array}{l}\text { Hybrid stator } \\
\text { current (A) }\end{array}$ & $\begin{array}{l}\text { Classical stator } \\
\text { voltage (V) }\end{array}$ & $\begin{array}{l}\text { Hybrid stator } \\
\text { voltage (V) }\end{array}$ & $\begin{array}{c}\text { Classical power } \\
\text { consumption }(\mathrm{W})\end{array}$ & $\begin{array}{c}\text { Hybrid power } \\
\text { consumption (W) }\end{array}$ \\
\hline$\overline{1}$ & 0.704 & 1.1 & 87.79 & 89.9 & 187.4 & 296.70 \\
\hline 2 & 1.722 & 1.4 & 98.25 & 98.9 & 502.4 & 415.40 \\
\hline 3 & 2.320 & 2.2 & 111.60 & 111.4 & 776.7 & 735.20 \\
\hline 4 & 2.540 & 2.6 & 126.60 & 125.6 & 994.7 & 979.70 \\
\hline 5 & 2.809 & 2.8 & 141.10 & 143.5 & 1285.2 & 1205.40 \\
\hline 6 & 3.112 & 2.9 & 154.70 & 155.6 & 1443.4 & 1353.75 \\
\hline 7 & 3.550 & 3.1 & 167.90 & 166.1 & 1788.1 & 1544.70 \\
\hline 8 & 3.653 & 3.6 & 178.50 & 180.3 & 1954.6 & 1947.24 \\
\hline 9 & 3.890 & 3.7 & 188.00 & 188.7 & 2193.9 & 2094.60 \\
\hline 10 & 4.168 & 3.8 & 196.70 & 196.4 & 2454.8 & 2238.90 \\
\hline 11 & 4.630 & 4.2 & 206.80 & 203.9 & 2872.5 & 2569.20 \\
\hline 12 & 4.871 & 4.5 & 212.60 & 211.8 & 3106.1 & 2859.30 \\
\hline 13 & 4.972 & 4.9 & 219.80 & 219.2 & 3277.2 & 3222.40 \\
\hline 14 & 5.166 & 5.3 & 225.30 & 225.1 & 3487.6 & 3379.10 \\
\hline 15 & 5.622 & 5.6 & 230.40 & 229.9 & 3884.6 & 3862.32 \\
\hline 16 & 5.981 & 5.8 & 236.10 & 223.7 & 4235.6 & 4066.40 \\
\hline 17 & 6.247 & 5.9 & 241.70 & 237.8 & 4524.6 & 4209.10 \\
\hline 18 & 6.319 & 6.2 & 242.60 & 241.0 & 4592.4 & 4482.60 \\
\hline
\end{tabular}

Table 5: Power consumption

\begin{tabular}{|c|c|c|c|c|c|}
\hline $\begin{array}{l}\text { Load } \\
\text { torque }(\mathrm{Nm})\end{array}$ & $\begin{array}{r}\text { Without control } \\
\text { consumption (W) }\end{array}$ & $\begin{array}{l}\text { Classic power } \\
\text { consumption (W) }\end{array}$ & $\begin{array}{l}\text { Hybrid power } \\
\text { consumption (W) }\end{array}$ & $\begin{array}{l}\text { Power saving using } \\
\text { classical (W) }\end{array}$ & $\begin{array}{l}\text { Power saving using } \\
\text { Hybrid (W) }\end{array}$ \\
\hline 1 & 4600 & 187.4 & 296.70 & 4412.6 & 4303.0 \\
\hline 2 & 4600 & 502.4 & 415.40 & 4097.6 & 4185.0 \\
\hline 3 & 4600 & 776.7 & 735.20 & 3823.3 & 3865.0 \\
\hline 4 & 4600 & 994.7 & 979.70 & 3605.3 & 3620.0 \\
\hline 5 & 4600 & 1285.2 & 1205.40 & 3314.2 & 3395.0 \\
\hline 6 & 4600 & 1443.4 & 1353.75 & 3156.6 & 3246.0 \\
\hline 7 & 4600 & 1788.1 & 1544.70 & 2811.1 & 3055.0 \\
\hline 8 & 4600 & 1954.6 & 1947.24 & 2645.2 & 2653.0 \\
\hline 9 & 4600 & 2193.9 & 2094.60 & 2406.9 & 2505.0 \\
\hline 10 & 4600 & 2454.8 & 2238.90 & 2145.2 & 2361.0 \\
\hline 11 & 4600 & 2872.5 & 2569.20 & 1727.5 & 2031.0 \\
\hline 12 & 4600 & 3106.1 & 2859.30 & 1493.1 & 1741.0 \\
\hline 13 & 4600 & 3277.2 & 3222.40 & 1322.8 & 1378.0 \\
\hline 14 & 4600 & 3487.6 & 3379.10 & 1112.8 & 1221.0 \\
\hline 15 & 4600 & 3884.6 & 3862.32 & 715.4 & 737.7 \\
\hline 16 & 4600 & 4235.6 & 4066.40 & 364.4 & 533.6 \\
\hline 17 & 4600 & 4524.6 & 42091.10 & 75.4 & 390.9 \\
\hline 18 & 4600 & 4592.4 & 4482.60 & 7.6 & 117.4 \\
\hline
\end{tabular}


Int. J. Syst. Signal Control Eng. Appl., 4 (4-6): 62-68, 2011

\begin{tabular}{|c|c|c|c|c|c|}
\hline $\begin{array}{l}\text { Load } \\
\text { torque }(\mathrm{Nm})\end{array}$ & $\begin{array}{l}\text { Without control } \\
\text { operating cost (JD) }\end{array}$ & $\begin{array}{l}\text { Classical control } \\
\text { operating cost (JD) }\end{array}$ & $\begin{array}{l}\text { Hybrid control } \\
\text { operating cost (JD) }\end{array}$ & $\begin{array}{l}\text { Operating cost saving } \\
\text { using classical (JD) }\end{array}$ & $\begin{array}{c}\text { Operating cost saving } \\
\text { using hybrid (JD) }\end{array}$ \\
\hline 1 & 0.225 & 0.009 & 0.015 & 0.216 & 0.210 \\
\hline 2 & 0.225 & 0.025 & 0.020 & 0.200 & 0.204 \\
\hline 3 & 0.225 & 0.038 & 0.036 & 0.186 & 0.188 \\
\hline 4 & 0.225 & 0.049 & 0.048 & 0.176 & 0.176 \\
\hline 5 & 0.225 & 0.063 & 0.059 & 0.162 & 0.165 \\
\hline 6 & 0.225 & 0.071 & 0.066 & 0.154 & 0.158 \\
\hline 7 & 0.225 & 0.088 & 0.076 & 0.137 & 0.149 \\
\hline 8 & 0.225 & 0.096 & 0.095 & 0.129 & 0.129 \\
\hline 10 & 0.225 & 0.120 & 0.110 & 0.105 & 0.115 \\
\hline 11 & 0.225 & 0.141 & 0.126 & 0.084 & 0.099 \\
\hline 12 & 0.225 & 0.152 & 0.140 & 0.073 & 0.084 \\
\hline 13 & 0.225 & 0.161 & 0.158 & 0.064 & 0.067 \\
\hline 14 & 0.225 & 0.171 & 0.166 & 0.054 & 0.059 \\
\hline 15 & 0.225 & 0.190 & 0.189 & 0.034 & 0.035 \\
\hline 16 & 0.225 & 0.208 & 0.199 & 0.017 & 0.025 \\
\hline 17 & 0.225 & 0.222 & 0.206 & 0.003 & 0.018 \\
\hline 18 & 0.225 & 0.225 & 0.220 & 0.000 & 0.005 \\
\hline
\end{tabular}

- The Classical Optimal Control Method saving operating cost over that reaches 19886.15 $\mathrm{JD} \mathrm{year}^{-1}$ when compared with operating at case one

- The Hybrid Optimal Control Method saving operating cost over that reaches $21020.15 \mathrm{JD}_{\text {year }}{ }^{-1}$ compared with operating at case one

The previous results of the current study could be formulated, graphically as shown in Fig. 12. The price of the electrical power from Jordan electrical company for industrial participator is $\left(0.49 \mathrm{JD}^{* *} \mathrm{~W}^{-1}\right)$ :

$[* *]: 1 \mathrm{JD} \cong 1.3 \mathrm{US} \$$

\section{CONCLUSION}

Using the classical optimal control for saving power consumption is justified, numerically and experimentally by reducing the stator voltages and currents to minimum values. The Hybrid Optimal Control System which consists of classical control loop as a master loop to generate modulation index $\mathrm{MI}$ commands and fuzzy logic controller in a slave loop to correct the generated command in order to improve the response and performance of optimal control system. The Hybrid Optimal Control System such as the values obtained for: stator current, stator voltage, angular rotor speed and the electromagnetic torque are better when using hybrid approach comparing with classical one.
The transient time to reach steady state and the stability of the closed control loops for the values of stator current, stator voltage, angular speed and electromagnetic induced torque in both optimal control methods are satisfactory but this criterion in Hybrid Optimal Control System is better than Classical Optimal Control System.

\section{REFERENCES}

Gerla, G., 2005. Fuzzy logic programming and fuzzy control. Studia Logica, 79: 231-254.

Gnacinski, P., 2007. Energy saving work of frequency controlled induction cage machine. Energy Convers. Manage., 48: 919-926.

Kim, D.H., 2007. GA-PSO based vector control of indirect three phase induction motor. Applied Soft Comput., 7: 601-611.

Mohamed, H.R., 2001. Power Electronic, Hand Book. Academic press, San diago, ISBN-13: 978-0125816502, Pages: 895.

Pryymak, B., J.M. Moreno-Eguilaz and J. Peracaula, 2006. Neural network based flux optimization using a model of losses in induction motor drives. Math. Comput. Simul., 71: 290-298.

Serway, R.A. and J.W. Jewett, 2004. Physics for Scientists and Engineers with Modern Physics. 6th Edn., Brooks/Cole, Belmont.

Tipler, P., 2004. Physics for Scientists and Engineers: Mechanics. 5th Edn., Oscillations and Waves, New York. 